\title{
Árvore modelo frente a uma rede neural artificial para a modelagem chuva-vazão
}

\author{
Aline Bernarda DEBASTIANI ${ }^{1 *}$, Sílvio Luís RAFAELI NETO², Ricardo DALAGNOL ${ }^{2}$
}

\author{
${ }^{1}$ Programa de Pós-Graduação em Engenharia Florestal, Universidade do Estado de Santa Catarina, Lages, SC, Brasil. \\ ${ }^{2}$ Instituto Nacional de Pesquisas Espaciais (INPE), São José dos Campos, SP, Brasil. \\ *E-mail: aline.debastiani@gmail.com
}

Recebido em agosto/2018; Aceito em março/2019.

\begin{abstract}
RESUMO: O objetivo deste estudo é investigar o desempenho da árvore modelo (M5P) e sua sensibilidade à poda e comparação com o desempenho de uma Rede Neural Artificial (RNA) para a simulação da vazão média diária mensal. A motivação para esta análise está na maior simplicidade e velocidade de processamento da M5P comparado às RNAs e a carência de estudos aplicando este método na modelagem hidrológica. $\mathrm{O}$ estudo foi desenvolvido na bacia hidrográfica do Alto Canoas, tendo um delineamento experimental composto por um período de treinamento, um de validação cruzada e dois períodos de testes. A RNA utilizada foi a Multi Layer Perceptron (MLP), implementada no software MATLAB, e a M5P (com e sem poda), disponível do software WEKA. O algoritmo M5P se mostrou sensível à poda em somente metade dos tratamentos. A M5P apresentou bom ajuste na modelagem, porém a RNA apresentou desempenho superior em todos os tratamentos.
\end{abstract}

Palavras-chave: rede neural artificial; árvore de regressão; Bacia do Alto Canoas.

\section{Model tree in comparison to artificial neural network for Rainfall-runoff modeling}

\begin{abstract}
The aim of this study is to investigate the performance of the model tree (M5P) and its sensitivity to pruning and comparison to the performance of an Artificial Neural network (ANN) for the simulation of daily average discharge of the month. The motivation for this analysis is on simplicity and speed of processing M5P compared the RNAs. The study was developed in the Alto Canoas watershed, having an experiment consisting of a training period, a cross-validation and two testing periods. The ANN used was the Multi Layer Perceptron (MLP), implemented in MATLAB software, and M5P (with and without pruning), available from the WEKA software. M5P algorithm proved sensitive to pruning in half of the treatments. The M5P showed good fit in the modeling, but the RNA presented superior performance in all treatments.
\end{abstract}

Keywords: artificial neural network; regression tree; Basin Alto Canoas.

\section{INTRODUÇÃO}

Os modelos hidrológicos são ferramentas computacionais utilizadas como instrumento para a simulação das variáveis hidrológicas de uma bacia, dentre estas, a vazão no seu exutório. Os modelos são calibrados e validados para um período de observações, e a partir disso é possível realizar projeções para o futuro. As previsões de vazões são recursos fundamentais no âmbito do gerenciamento dos recursos hídricos, as quais podem ser analisadas como cenários ou prognósticos durante a etapa de elaboração dos planos de bacia.

As simulações hidrológicas podem ser realizadas em escala diária, mensal ou até mesmo sazonal. Quando em escala diária são importantes para previsão de eventos extremos, como de chuvas intensas, proporcionando o envio de alertas para a população em áreas de risco. Já as previsões médias mensais ou sazonais não consideram os eventos extremos, e são utilizadas para o planejamento das operações de sistemas de recursos hídricos, como a geração de energia nas hidrelétricas (BATISTA, 2009) e disponibilidade hídrica sazonal em bacias rurais (OLIVEIRA et al., 2014).

Os modelos hidrológicos podem ser classificados como conceituais, baseados em processos físicos, ou baseados em dados, quando utilizam de métodos estatísticos, estocásticos ou ainda por métodos que aprendem através dos dados, conhecidos como métodos de aprendizado de máquinas. Os modelos baseados em processos físicos têm vantagens sobre os baseados em dados por representarem os fenômenos físicos e, uma vez calibrados para uma bacia, podem ser utilizados com maior segurança para previsões. No entanto, como muitas vezes as observações das variáveis hidroclimáticas e ambientais são escassas, a implementação e validação de um modelo físico torna-se mais difícil, dando vantagem aos modelos baseados em dados por representarem os processos não-lineares de uma bacia mais diretamente (TUCCI, 2005).

Entre as várias abordagens dos métodos de aprendizado de máquinas, a mais conhecida e utilizada na hidrologia são as Redes Neurais Artificiais (RNA) (SOLOMATINE; DULAL, 2003). As RNAs são inspiradas na estrutura e funcionamento do cérebro humano, representam processos de forma nãolinear, e o aprendizado consiste no ajuste dos pesos sinápticos para que ao processar a entrada de dados, a saída da simulação corresponda à saída esperada (HAYKIN, 2001). Diversas pesquisas têm encontrado excelentes resultados ao utilizarem RNAs para a modelagem chuva-vazão, dentre os quais estão os relatados por Batista (2009), Sousa; Sousa (2010), Castro (2011), Escarião et al. (2012), Oliveira et al. (2013) e Oliveira et al. (2014).

Uma das dificuldades na utilização de RNAs é a interpretação de como o algoritmo processou os dados de entrada e produziu determinado resultado, sendo, com isso, denominados de sistemas caixas-pretas. No entanto, no 
universo dos métodos de aprendizado de máquina existem outras abordagens como as árvores de regressão, que aproximam o usuário do funcionamento do modelo. As árvores de regressão são um tipo de árvore de decisão que combina a capacidade de classificação conhecida das árvores de decisão e a possibilidade de resolver problemas de regressão em uma árvore só, em que os nós das folhas foram concebidos como modelos de regressão, portanto podem ser previstos valores numéricos contínuos (WITTEN et al., 2011).

Um dos métodos de árvores de regressão é o algoritmo da árvore modelo, conhecido também como M5 ou M5P. O critério de divisão para o algoritmo M5P é baseado em tratar o desvio padrão dos valores da classe que atingem um nó como uma medida do erro nesse nó. O cálculo da redução esperada para esse erro, é como um resultado de teste de cada atributo desse nó. Depois de avaliar todos os grupos possíveis, o algoritmo escolhe aquele que minimiza o erro previsto (QUINLAN, 1992).

As árvores modelos são praticamente desconhecidas na modelagem chuva-vazão, sendo encontrado apenas o estudo desenvolvido por Solomatine; Dulal (2003). Nesse sentido, outro aspecto em aberto que pode influenciar na modelagem hidrológica é a utilização do critério de poda. A poda é uma técnica de redução da árvore que tem a função de impedir que estas sejam demasiadamente grandes e complexas, a fim de evitar o problema conhecido como overfitting, em que as árvores tornam-se especialistas no conjunto de dados de treinamento e perdem a capacidade de extrapolar seus resultados, obtendo baixa exatidão na simulação com o conjunto de dados de teste. Depois que a árvore é construída, alguns nós intermediários são transformados em nós terminais, ou folhas. Este processo aumenta o erro na fase de treinamento, porém reduz o erro no teste, desenvolvendo uma árvore menor, mais interpretável e com melhor capacidade de previsões (WITTEN et al., 2011).

Tendo em vista a carência de estudos da aplicação de árvores de regressão para simulação do processo chuva-vazão de bacias hidrográficas, este estudo tem por objetivo realizar a simulação da resposta hidrológica para a bacia do Alto Canoas através das técnicas de árvore de regressão e sua comparação com um método tradicional de redes neurais artificiais, buscando atender os objetivos específicos: (1) testar o desempenho das árvores de regressão na simulação hidrológica; (2) investigar a contribuição da poda no desempenho da árvore modelo (M5P); (3) avaliar a influência das variáveis hidroclimáticas na construção da árvore de regressão; (4) comparar o desempenho da árvore modelo com uma RNA para a simulação da vazão média diária do mês.

\section{MATERIAL E MÉTODOS}

2.1. Área de estudo e série histórica

O estudo foi realizado na sub-bacia do Rio Canoas, denominada bacia do Alto Canoas (Figura 1). A bacia do Alto Canoas apresenta uma área de cerca de $1980 \mathrm{~km}^{2}$ cujo território abrange os municípios de Urubici, Bocaina do Sul, Rio Rufino e Bom Retiro, do estado de Santa Catarina, Brasil.

$\mathrm{O}$ relevo da área apresenta altitudes que variam de 839 a $1.816 \mathrm{~m}$, caracterizado por uma área de platô, seguida por fortes depressões em direção ao vale, em que predominam Neossolos Litólicos e Cambisolos Húmicos.

As classes de uso e cobertura da terra predominantes são os campos de altitude, floresta primária do tipo Floresta Ombrófila Mista, reflorestamentos de Pinus spp., culturas agrícolas temporárias e áreas urbanas. As classes de floresta primária e campo somam cerca de $80 \%$ da área de estudo, situadas nas encostas e topos de morros, respectivamente. As áreas mais baixas da bacia são ocupadas pelas demais classes (ANTUNES, 2015).

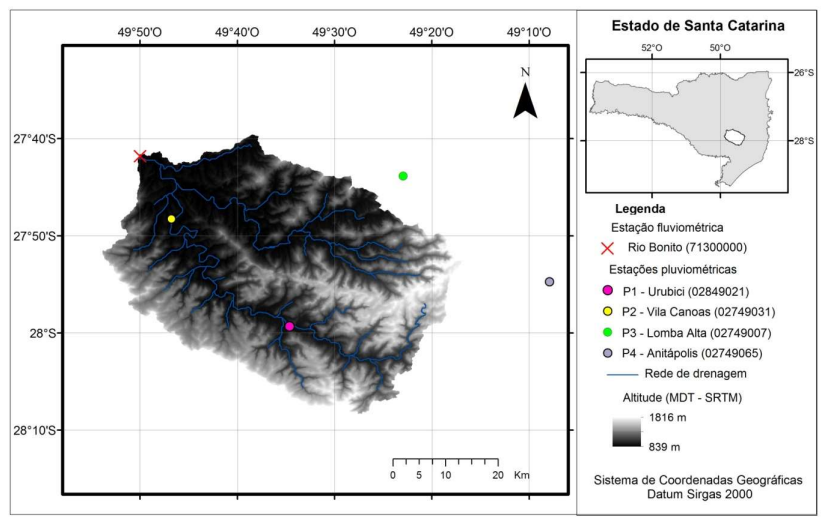

Figura 1. Localização da Bacia hidrográfica do Alto Canoas, Santa Catarina, Brasil.

Figure 1. Location of the Alta Canoas Basin, Santa Catarina, Brazil.

\subsection{2 Dados observados}

Foram adquiridas séries históricas de precipitação média diária do mês das estações pluviométricas de Urubici (P1) (código: 02849021), Vila Canoas (P2) (código: 02749031), Lomba Alta (P3) (código: 02749007) e Anitápolis (P4) (código: 02749065), e vazão média diária do mês da estação fluviométrica Rio Bonito (código: 71300000), através do portal Hidro Web (http://hidroweb.ana.gov.br/). A área de influência das estações P1, P2, P3, e P4 corresponde, respectivamente, a $47 \%, 34 \%, 16 \%$ e $3 \%$ da área da bacia, de acordo com a metodologia dos polígonos de Thiessen.

As médias diárias do mês foram calculadas pela razão entre o total precipitado no mês e o número de dias de cada mês. Utilizou-se a média diária mensal, tendo o número de dias do mês como fator de ponderação na construção da série para evitar variações decorrentes do número de dias de cada mês.

As séries históricas obtidas no período foram divididas em quatro subconjuntos amostrais, sendo: 01/1980 a 12/1984 para treinamento dos modelos; 01/1985 a 05/1987 para a validação cruzada do treinamento; 01/1988 a 12/1989 como período de teste 1; e 01/1998 a 12/1999 como período de teste 2. As proporções dos subconjuntos foram semelhantes as utilizadas por Sousa; Sousa (2010) e Oliveira et al. (2014). Estes períodos fazem parte de um delineamento experimental e foram escolhidos devido à disponibilidade e ausência de falhas, sendo que o teste 1 é composto pelos anos seguintes aos utilizados para o treinamento e validação, e o período de teste 2 abrange a série de 10 anos à frente.

Para caracterizar o comportamento da série histórica foi realizada uma análise exploratória das variáveis de entrada e de saída de água do sistema. A análise exploratória foi realizada através de estatísticas descritivas dos dados e correlação linear de Pearson.

\subsection{Estrutura da RNA para a simulação da vazão média diária do mês}

A RNA utilizada foi a Multi Layer Perceptron (MLP) aplicada no software MATLAB 2014a com o Neural Network Toolbox. A arquitetura da MLP foi constituída de três camadas definidas previamente a partir de testes, sendo elas: entrada, 
oculta e saída. O algoritmo de aprendizado escolhido foi o de retropropagação de Levenberg-Marquardt (HAGAN; MENHAJ, 1994). Foi escolhida a função de ativação tangente hiperbólica sigmoidal, esta que comprime os valores em um intervalo de -1 a 1.

Os vetores de entrada foram padronizados em uma mesma escala, sendo média igual a 0 e desvio padrão igual a 1 , a fim de melhorar a convergência (FU, 1994).

Para garantir um bom número de neurônios na camada oculta, calculou-se o número de neurônios ótimo. Para tal, utilizou-se uma relação de aproximadamente 10 vezes mais equações de treinamento (Equação 1) do que de pesos (Equação 2) na camada oculta, calculando o número de neurônios ótimos (HEATH, 2010).

Neurônios $=\left(-1+\left(\operatorname{Amostras}_{\text {Treino }}-0\right) /(\mathrm{I}+0+1)\right) /$ Razão $\quad$ (Eq. 1) Pesos $=((\mathrm{I}+1) *$ Neurônios $+($ Neurônios +1$)) * 0 \quad$ (Eq. 2$)$

em que Neurônios: número de neurônios ótimos; Amostras Treino: número de amostras de treino; O: número de vetores de saída; I: número de vetores de entrada; Razão: relação de aproximadamente 10 vezes mais amostras de treinamento do que número de pesos da camada oculta.

A partir do número de neurônios ótimo, testou-se uma variação em torno de \pm 5 neurônios na camada oculta, a fim de testar a arquitetura que proporcionasse a melhor solução para o problema. Também foram testadas dez inicializações aleatórias dos pesos sinápticos.

O treinamento da MLP foi realizado sobre o subconjunto de 01/1980 a 12/1984. O subconjunto de 01/1985 a 05/1987 foi utilizado como validação para critério de parada do treinamento, onde o algoritmo, a cada iteração, testou se o modelo havia convergido ou não. Para avaliação final do desempenho da RNA, utilizou-se os subconjuntos de 1/1988 a 12/1989 (Teste 1), e 01/1998 a 12/1999 (Teste 2). Estes anos foram escolhidos pela disponibilidade, por serem séries ininterruptas e pelas características das séries de dados.

\subsection{Estrutura da árvore modelo para a simulação da vazão média diária do mês}

Para a simulação da vazão média diária do mês por árvores de regressão foi utilizado o algoritmo da árvore modelo, denominado como M5P no aplicativo WEKA (Waikato Environment for Knowledge Analysis). As árvores são geradas a partir de um conjunto de dados de treinamento sendo que, em cada nó, o algoritmo escolhe os atributos que mais eficientemente subdividem o conjunto das amostras em subconjuntos homogêneos e caracterizados por sua classe. O critério é o ganho de informação obtido na escolha do atributo para subdivisão (QUINLAN, 1993).

$\mathrm{O}$ treinamento foi realizado em modo Percentage Split com os mesmos dados e proporções utilizadas pela MLP. Após definidas as regras, foi aplicado o mesmo para a estimativa da vazão média diária do mês nos períodos de testes 1 e 2 .

\subsection{Composição dos vetores da camada de entrada}

Os vetores de entrada da MLP e da M5P foram constituídos de 4 tratamentos, buscando verificar o desempenho com a utilização apenas da precipitação das estações localizadas dentro da área de estudo (P1, P2), utilização de todas as estações com área de influência sobre a bacia (P1, P2, P3, P4), utilização da precipitação média diária do mês ponderada pela área de influência de cada estação (PP1, PP2, PP3, PP4) e a influência da adição da vazão do mês anterior como entrada para a modelagem $\left(\mathrm{P} 1, \mathrm{P} 2, \mathrm{P} 3, \mathrm{P} 4, \mathrm{Q}_{\mathrm{t}}\right.$ 1).

\subsection{Avaliação dos modelos}

A Figura 2 apresenta o delineamento experimental realizado neste estudo.

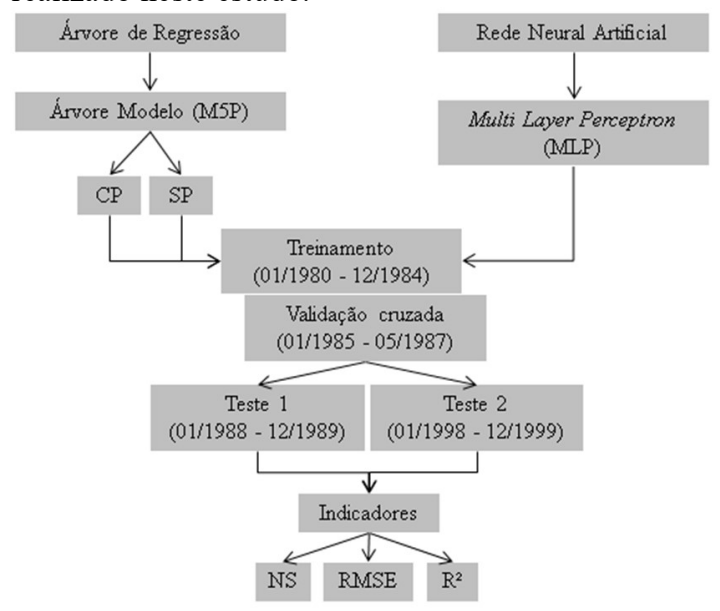

*em que, CP: com poda; SP: sem poda; $\mathrm{R}^{2}$ : coeficiente de determinação; RMSE: Raiz do Erro Médio Quadrático; NS: índice de Nash; Sutcliffe.

Figura 2. Delineamento experimental.

Figure 2. Experimental design.

A eficácia da MLP e da M5P foram medidas sobre os resíduos das vazões simuladas pelos modelos em relação às vazões observadas. Os parâmetros utilizados para a avaliação foram o índice de Nash; Sutcliffe (1970) (NS), coeficiente de determinação $\left(\mathrm{R}^{2}\right)$ e Raiz do Erro Médio Quadrático (RMSE). O desempenho do algoritmo M5P foi avaliado comparando o processo com poda (CP) e sem a realização da poda (SP). Também se analisou a influência das variáveis hidroclimáticas para a construção da árvore de regressão.

\section{RESULTADOS}

3.1. Análise exploratória sobre a série histórica de dados

A Tabela 1 apresenta as estatísticas descritivas das séries utilizadas como vetores de entrada e saída da MLP e M5P. O período de treinamento registrou, em média, o maior volume de precipitação, sendo estes registrados pelas estações de Urubici (P1), Lomba Alta (P3) e Anitápolis (P4). A estação pluviométrica Anitápolis ( $\mathrm{P} 4)$ registrou a maior média diária do mês de precipitação no treinamento e teste 1 , e maior volume médio diário por mês $(13,87)$ no teste 2 , comparado com as demais estações pluviométricas.

Os coeficientes de variação $(\mathrm{CV}>47 \%)$ implicam que há alta dispersão entre os valores de precipitação média diária do mês. Isto deve estar relacionado com o efeito sazonal, uma vez que os valores estão agrupados na escala mensal (vazão média diária do mês). Os valores médios dos períodos de treinamento e teste 2 são maiores do que a mediana, o que indica a assimetria positiva dos dados (assimetria $>1,09$ ). Os valores médios das precipitações no período de teste 1 para as estações Vila Canoas (P2) e Anitápolis (P4) são menores do que a média, sendo indicadores de baixa assimetria, 0,09 e 0,17 respectivamente.

O período de treinamento apresentou a maior média $(75,28$ $\mathrm{m}^{3} / \mathrm{s}$ ) e dispersão (CV 74,13\%) da vazão média diária do mês, demonstrando que este período tem comportamento mais disperso, comparado aos períodos de testes, o que pode ser 
considerado bom para o treinamento dos modelos, pois inclui uma maior variabilidade de situações de entradas e saídas, incluindo até mesmo os extremos de chuva, 1983 e 1984, período de ocorrência do El Niño.

De acordo com as vazões máximas e média, o período de teste 2 é o que mais se assemelha com o período utilizado para treinamento. Porém, se levar em consideração o $\mathrm{CV} \%$, o período de teste 1 é o mais parecido com o período de treinamento.
Os coeficientes de correlações lineares de Pearson entre as séries são apresentados na Tabela 2.

O grau de dependência estatística linear entre as séries históricas de precipitação e vazão são positivas. Sendo que as correlações lineares variaram de 0,59 a 0,78 . A maior correlação ocorreu com a estação P1 que possui maior área de contribuição, e a menor correlação ocorreu com a estação mais distante do exutório (P4) e que possui menor área de influência na bacia.

Tabela 1. Estatísticas das precipitações médias diárias do mês e vazão média diária do mês nos subconjuntos de treinamento e testes.

Table 1. Statistics of average daily rainfall of the month and the average daily discharge of the month in subsets of training and testing.

\begin{tabular}{ccccccc}
\hline Subconjunto de dados & Parâmetros & P1 $(\mathrm{mm})$ & $\mathrm{P} 2(\mathrm{~mm})$ & $\mathrm{P} 3(\mathrm{~mm})$ & $\mathrm{P} 4(\mathrm{~mm})$ & $\mathrm{Q}\left(\mathrm{m}^{3} / \mathrm{s}\right)$ \\
\hline & Média & 4,79 & 4,37 & 4,71 & 5,91 & 75,28 \\
Treinamento & Mediana & 4,26 & 4,13 & 4,23 & 5,67 & 59,04 \\
01/1980 a 12/1984 & Máxima & 19,44 & 19,40 & 22,19 & 21,10 & 297,95 \\
& Mínima & 0,55 & 0,91 & 1,08 & 0,94 & 19,36 \\
& Assimetria & 2,07 & 2,72 & 2,86 & 2,30 & 2,08 \\
& CV\% & 63,71 & 64,76 & 68,51 & 61,15 & 74,13 \\
\hline & Média & 3,68 & 3,18 & 3,70 & 4,35 & 60,17 \\
Teste 1 & Mediana & 3,11 & 3,32 & 3,05 & 4,53 & 49,20 \\
01/1988 a 12/1989 & Máxima & 10,57 & 6,58 & 9,42 & 8,66 & 170,83 \\
& Mínima & 0,24 & 0,17 & 0,37 & 0,14 & 18,79 \\
& Assimetria & 1,49 & 0,09 & 1,01 & 0,17 & 1,41 \\
Teste 2 & CV\% & 66,16 & 51,80 & 63,43 & 55,53 & 59,63 \\
\hline & Média & 4,31 & 4,90 & 4,49 & 4,87 & 66,32 \\
01/1998 a 12/1999 & Mediana & 3,85 & 4,70 & 4,18 & 4,59 & 51,45 \\
& Máxima & 12,12 & 12,27 & 10,70 & 13,87 & 158,59 \\
& Mínima & 1,21 & 1,20 & 1,79 & 1,61 & 23,63 \\
& Assimetria & 1,62 & 1,26 & 1,18 & 1,81 & 5,09 \\
\hline
\end{tabular}

Tabela 2. Matriz de correlação linear de Pearson entre as séries de precipitações (P) e de vazões (Q) utilizadas para compor os subconjuntos de dados.

Table 2. Pearson linear correlation matrix between series of rainfall (P) and discharges (Q) used to compose the subsets of data.

\begin{tabular}{llllll}
\hline & P1 & P2 & P3 & P4 & Q \\
\hline P1 & 1,00 & & & & \\
P2 & 0,87 & 1,00 & & & \\
P3 & 0,91 & 0,86 & 1,00 & 1,00 & 1,00 \\
P4 & 0,80 & 0,68 & 0,76 & 0,59 & \\
Q & 0,78 & 0,72 & 0,75 & 0,59 \\
\hline
\end{tabular}

3.2. Desempenho da árvore modelo (M5P)

Os indicadores de desempenho do algoritmo M5P estão apresentados na Tabela 3.

Para a fase de treinamento o NS variou de $0,573 \mathrm{com}$ RMSE de $31,173 \mathrm{~m}^{3} / \mathrm{s}$ (tratamento 1 - CP) a NS =0,708 com RMSE de $31,549 \mathrm{~m}^{3} / \mathrm{s}$ (tratamento 2 - SP). Na fase de treinamento, apenas o tratamento 3 apresentou melhor desempenho com a realização da poda, indicando que a precipitação ponderada pela área de influência possui informações redundantes e os valores modelados tiveram uma maior aproximação aos observados quando retiradas essas informações redundantes.

Tabela 3. Desempenho do algoritmo M5P sem poda (SP) e com poda (CP) para a simulação da vazão nos períodos de treinamento e testes para os diferentes tratamentos de entrada do modelo.

Table 3. Performance of M5P algorithm without pruning (SP) and with pruning (CP) for the discharge simulation during periods of training and testing regarding the different treatments of model input.

\begin{tabular}{|c|c|c|c|c|c|c|c|c|c|c|}
\hline \multirow[t]{2}{*}{ Tratamentos } & & \multicolumn{3}{|c|}{$\begin{array}{c}\text { Treinamento } \\
\text { Avaliação com validação cruzada }\end{array}$} & \multicolumn{3}{|c|}{ Teste 1} & \multicolumn{3}{|c|}{ Teste 2} \\
\hline & & $\mathrm{R}^{2}$ & $\operatorname{RMSE}\left(\mathrm{m}^{3} / \mathrm{s}\right)$ & NS & $\mathrm{R}^{2}$ & $\operatorname{RMSE}\left(\mathrm{m}^{3} / \mathrm{s}\right)$ & NS & $\mathrm{R}^{2}$ & $\operatorname{RMSE}\left(\mathrm{m}^{3} / \mathrm{s}\right)$ & NS \\
\hline \multirow{2}{*}{ 1) $\mathrm{P} 1, \mathrm{P} 2$} & SP & 0,621 & 31,627 & 0,715 & 0,476 & 27,663 & 0,361 & 0,605 & 23,704 & 0,583 \\
\hline & $\mathrm{CP}$ & 0,678 & 37,173 & 0,573 & 0,479 & 27,222 & 0,378 & 0,683 & 20,898 & 0,676 \\
\hline \multirow{2}{*}{ 2) $\mathrm{P} 1, \mathrm{P} 2, \mathrm{P} 3, \mathrm{P} 4$} & SP & 0,617 & 31,549 & 0,708 & 0,449 & 27,860 & 0,359 & 0,595 & 23,787 & 0,580 \\
\hline & $\mathrm{CP}$ & 0,634 & 36,289 & 0,593 & 0,454 & 28,417 & 0,327 & 0,561 & 25,547 & 0,516 \\
\hline \multirow{2}{*}{ 3) PP1, PP2, PP3, PP4 } & SP & 0,612 & 36,455 & 0,590 & 0,449 & 27,863 & 0,359 & 0,595 & 23,795 & 0,580 \\
\hline & $\mathrm{CP}$ & 0,634 & 36,288 & 0,593 & 0,409 & 28,589 & 0,320 & 0,548 & 25,821 & 0,505 \\
\hline \multirow{2}{*}{ 4) P1, P2, P3, P4, Qt-1 } & SP & 0,628 & 31,247 & 0,667 & 0,603 & 23,087 & 0,568 & 0,645 & 22,007 & 0,641 \\
\hline & $\mathrm{CP}$ & 0,653 & 35,598 & 0,609 & 0,611 & 22,735 & 0,581 & 0,697 & 20,288 & 0,641 \\
\hline
\end{tabular}


A M5P apresentou melhores desempenhos ao realizar a poda, nos tratamentos 1 e 4 dos períodos de testes 1 e 2 , possivelmente devido a $\mathrm{P} 1$ e $\mathrm{P} 2$ presentes nestes tratamentos.

A M5P no período de teste 2 apresentou desempenho superior ao se comparar com o período de teste 1 , possivelmente por este período ser em média mais parecido com o período de treinamento.

\subsection{Desempenho da multi layer perceptron}

O desempenho da MLP para a simulação da vazão média diária do mês, na fase de treinamento, está apresentado na Tabela 4 e para os períodos de testes na Tabela 5 .
O desempenho da RNA na fase de treinamento teve NS variando de 0,760 com RMSE de 30,472 $\mathrm{m}^{3} / \mathrm{s}$ (tratamento 3) a $\mathrm{NS}=0,973 \mathrm{com} \mathrm{RMSE}$ de $21,046 \mathrm{~m}^{3} / \mathrm{s}$ (tratamento 4). O número de neurônios na camada intermediária que produziu os melhores resultados variou de 3 a 5 .

Ocorre uma divergência ao se considerar os índices de desempenho no período de teste. Considerando o $\mathrm{R}^{2}$ que indica precisão, e o RMSE dos tratamentos na fase de teste, o desempenho para todos os tratamentos, foi superior no período de teste 2. Porém, se levar em consideração o valor do NS que é o indicador mais utilizado para este tipo de estudo, o período de teste 1 foi superior.

Tabela 4. Desempenho da MLP na fase de treinamento e arquitetura para os diferentes tratamentos de entrada do modelo.

Table 4. Performance of MLP training phase and architecture for the different treatments of model input.

\begin{tabular}{|c|c|c|c|c|}
\hline \multirow{2}{*}{ Tratamentos } & \multicolumn{3}{|c|}{$\begin{array}{c}\text { Treinamento } \\
\text { Avaliação com validação cruzada }\end{array}$} & \multirow{2}{*}{$\begin{array}{l}\text { Número de Neurônios: } \\
\text { Entrada/Oculta/Saída }\end{array}$} \\
\hline & $\mathrm{R}^{2}$ & $\operatorname{RMSE}\left(\mathrm{m}^{3} / \mathrm{s}\right)$ & NS & \\
\hline 1) $\mathrm{P} 1, \mathrm{P} 2$ & 0,689 & 30,847 & 0,771 & $2 / 5 / 1$ \\
\hline 2) P1, P2, P3, P4 & 0,702 & 30,252 & 0,757 & $4 / 5 / 1$ \\
\hline 3) PP1, РP2, РP3, РP4 & 0,697 & 30,472 & 0,760 & $4 / 4 / 1$ \\
\hline 4) P1, P2, P3, P4, Qt-1 & 0,860 & 21,046 & 0,973 & $5 / 3 / 1$ \\
\hline
\end{tabular}

Tabela 5. Desempenho da MLP para a simulação da vazão para os períodos de teste 1 e 2 para os diferentes tratamentos.

Table 5. Performance of MLP discharge simulation to test periods 1 and 2 for the different treatments.

\begin{tabular}{lcccccc}
\hline \multirow{2}{*}{ Tratamentos } & \multicolumn{3}{c}{ Teste 1 } & \multicolumn{3}{c}{ Teste 2 } \\
\cline { 2 - 7 } & $\mathrm{R}^{2}$ & $\mathrm{RMSE}\left(\mathrm{m}^{3} / \mathrm{s}\right)$ & $\mathrm{NS}$ & $\mathrm{R}^{2}$ & $\mathrm{RMSE}\left(\mathrm{m}^{3} / \mathrm{s}\right)$ & $\mathrm{NS}$ \\
\hline 1) P1, P2 & 0,508 & 25,941 & 0,888 & 0,582 & 25,008 & 0,699 \\
2) P1, P2, P3, P4 & 0,474 & 27,186 & 0,864 & 0,625 & 24,273 & 0,622 \\
3) PP1, PP2, PP3, PP4 & 0,487 & 29,491 & 0,776 & 0,621 & 24,481 & 0,611 \\
4) P1, P2, P3, P4, Qt-1 & 0,578 & 23,205 & 0,872 & 0,684 & 22,684 & 0,752 \\
\hline
\end{tabular}

\subsection{Comparação do desempenho da MLP e M5P}

$\mathrm{Na}$ Tabela 6, pode ser observado o desempenho dos algoritmos MLP e M5P para cada um dos conjuntos de dados, nos períodos de teste 1 e de teste 2 .

Para os algoritmos MLP e M5P, verifica-se que, para o tratamento 1 , o qual inclui apenas as estações que estão no interior da área de estudo e com maior área de contribuição definida pelos polígonos de Thiessen (P1 e P2), o desempenho é ligeiramente superior ao tratamento $2 \mathrm{em}$ que foram incluídas as estações P3 e P4, localizadas no entorno da bacia. A utilização da precipitação ponderada (tratamento 3) apresentou NS semelhante, ou até mesmo igual, comparada à utilização da precipitação pontual (tratamento 2), nos períodos de teste 1 e 2 .

A adição da vazão média diária do mês anterior como entrada (tratamento 4) produziu um pequeno acréscimo no desempenho dos algoritmos MLP e M5P, comparando-se à não utilização (tratamento 2).

Tabela 6. Desempenho dos algoritmos para a simulação da vazão, para os períodos de teste 1 e 2 , nos diferentes tratamentos. Table 6. Performance of algorithms for the discharge simulation for test periods 1 and 2 in different treatments.

\begin{tabular}{|c|c|c|c|c|c|c|c|c|c|c|c|c|}
\hline \multirow{3}{*}{ Tratamentos } & \multicolumn{6}{|c|}{ Período de Teste 1} & \multicolumn{6}{|c|}{ Período de Teste 2} \\
\hline & \multicolumn{3}{|c|}{ RNA (MLP) } & \multicolumn{3}{|c|}{ M5P } & \multicolumn{3}{|c|}{ RNA (MLP) } & \multicolumn{3}{|c|}{ M5P } \\
\hline & NS & $\mathrm{R}^{2}$ & $\begin{array}{c}\text { RMSE } \\
\left(\mathrm{m}^{3} / \mathrm{s}\right)\end{array}$ & NS & $\mathrm{R}^{2}$ & $\begin{array}{l}\text { RMSE } \\
\left(\mathrm{m}^{3} / \mathrm{s}\right)\end{array}$ & NS & $\mathrm{R}^{2}$ & $\begin{array}{c}\text { RMSE } \\
\left(\mathrm{m}^{3} / \mathrm{s}\right)\end{array}$ & NS & $\mathrm{R}^{2}$ & $\begin{array}{l}\text { RMSE } \\
\left(\mathrm{m}^{3} / \mathrm{s}\right)\end{array}$ \\
\hline 1) $\mathrm{P} 1, \mathrm{P} 2$ & 0,888 & 0,508 & 25,941 & $0,378^{*}$ & 0,479 & 27,222 & 0,699 & 0,582 & 25,008 & $0,676^{*}$ & 0,683 & 20,898 \\
\hline 2) $\mathrm{P} 1, \mathrm{P} 2, \mathrm{P} 3, \mathrm{P} 4$ & 0,864 & 0,474 & 27,186 & 0,359 & 0,449 & 27,860 & 0,622 & 0,625 & 24,273 & 0,580 & 0,595 & 23,787 \\
\hline 3) PP1, PP2, PP3, PP4 & 0,776 & 0,487 & 29,491 & 0,359 & 0,449 & 27,863 & 0,611 & 0,621 & 24,481 & 0,580 & 0,595 & 23,795 \\
\hline 4) $\mathrm{P} 1, \mathrm{P} 2, \mathrm{P} 3, \mathrm{P} 4, \mathrm{Q}_{\mathrm{t}-1}$ & 0,872 & 0,578 & 23,205 & $0,581 *$ & 0,611 & 22,735 & 0,752 & 0,684 & 22,684 & $0,641 *$ & 0,697 & 20,288 \\
\hline
\end{tabular}

Na Figura 3, é possível observar o comportamento da vazão média diária do mês, simulada pela MLP e M5P, em relação à vazão observada para o tratamento 4 , considerando que este foi o melhor desempenho para o período de teste 1 , em que incluem P1, P2, P3, P4 e $\mathrm{Q}_{\mathrm{t}-1}$.

Observa-se que a MLP e a M5P apresentaram valores simulados próximos entre si e do valor observado, sendo que, para algumas datas, os modelos subestimaram a vazão e também houve superestimativa. Um modelo não apresentou um único comportamento.
A MLP é o algoritmo que melhor simulou a vazão alcançando no teste 1 , NS de 0,872 e RMSE de $23,205 \mathrm{~m}^{3} / \mathrm{s}$ e a M5P obteve NS de 0,581 e RMSE de $22,735 \mathrm{~m}^{3} / \mathrm{s}$, tendo como entrada a precipitação de todas as estações pluviométricas e a vazão no tempo anterior (t-1).

No hidrograma da Figura 4 é demonstrado o comportamento da vazão média diária do mês observada e a simulada pela MLP e pela M5P para o período de teste 2 .

Para o período de teste 2 e tratamento 4 os modelos estudados apresentaram o melhor desempenho, sendo que a 
RNA alcançou NS de 0,752, RMSE de 22,684 $\mathrm{m}^{3} / \mathrm{s}$ e o algoritmo M5P obteve NS de 0,641 e RMSE de 20,288 m³.s.

$\mathrm{O}$ tratamento 4 foi responsável por fazer com que os dois algoritmos apresentassem comportamento semelhante, acredita-se que o mecanismo que possibilitou isso foi a correlação hidrológica da $\mathrm{Q}_{\mathrm{t}-1}$ com a $\mathrm{Q}_{\mathrm{t}}$, sendo recomendada sua inclusão. No período de teste 1 e 2, a MLP apresentou desempenho superior ao da M5P.

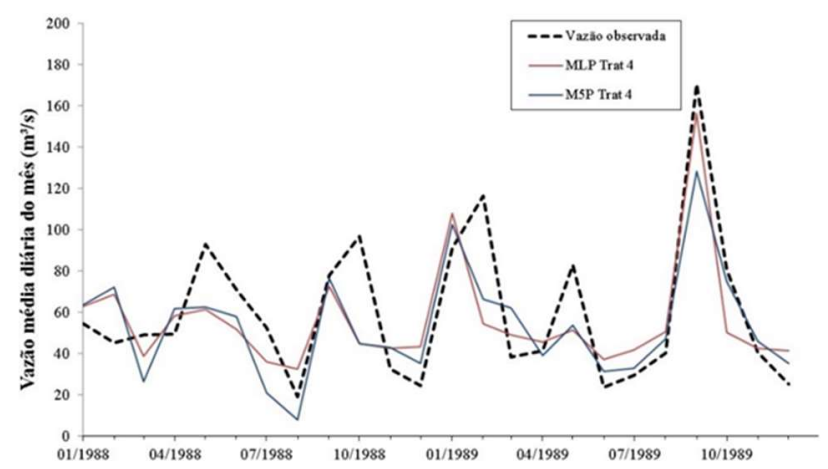

Figura 3. Hidrograma observado e simulado pela MLP e M5P no tratamento 4 e período de teste 1 .

Figure 3. Observed and simulated hydrograph by MLP and M5P on treatment 4 and test period 1 .

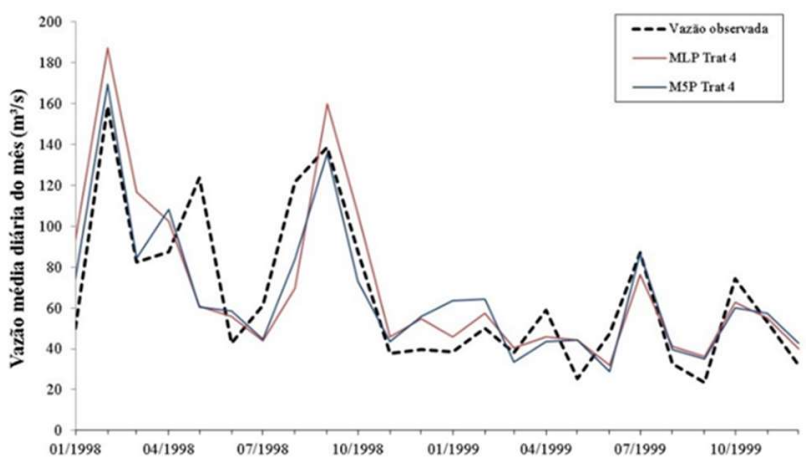

Figura 4. Hidrograma observado e simulado pela MLP e pela M5P no tratamento 4 e no período de teste 2 .

Figure 4. Observed and simulated hydrograph by MLP and M5P on treatment 4 and test period 2.

\section{DISCUSSÃO}

A série histórica utilizada para treinamento e teste 2 apresenta assimetria positiva. Esta mesma caracterização de dados foi encontrada por Gomes et al. (2011) para dados de precipitação na Paraíba.

Para a precipitação, a correlação varia de 0,68 a 0,91 , indicando que a precipitação registrada em uma estação varia de moderada a forte com a estação vizinha, de acordo com a classificação de Dancey; Reidy (2006). Este comportamento se justifica por se tratar da precipitação média diária do mês e está variar pouco entre estações próximas.

O desempenho dos algoritmos M5P e MLP, ao utilizar como variáveis de entrada apenas as estações pluviométricas dentro da área de estudo foi superior ao encontrado com a adição das demais estações com influência. Isto pode estar relacionado com o fato de os modelos redistribuírem a contribuição de cada vetor para a modelagem, dando menor importância aos vetores que apresentam maior representatividade sobre a precipitação que ocorre na bacia do Alto Canoas. Corroborando com estes resultados, Debastiani et al. (2016) estudaram a mesma bacia hidrográfica com RNA, porém com séries históricas diárias. Os autores encontraram NS de 0,913 ao utilizarem como entrada apenas as estações pluviométricas dentro da área de estudo e vazão do dia anterior $\left(\mathrm{P} 1, \mathrm{P} 2, \mathrm{Q}_{(\mathrm{t}-1)}\right)$, ao adicionar as demais estações com influência sobre a bacia (P3, P4) o desempenho da RNA caiu, NS = 0,907 , porém estes resultados ainda foram superiores ao encontrado no presente estudo.

Desempenho menos expressivo foi encontrado por Sousa; Sousa (2010) ao utilizarem apenas dados de precipitação. Os autores utilizaram uma MLP para prever vazões médias mensais da bacia hidrográfica do Rio Piancó, tendo como entrada a combinação e uso de cinco estações pluviométricas, sendo que a melhor arquitetura alcançou $\mathrm{R}^{2}$ de 0,92 e NS de 0,77 .

A utilização da precipitação pontual ou ponderada parece não ter causado mudança para o desempenho da modelagem, isso demonstra a capacidade das técnicas de inteligência artificial em ponderar os vetores de entrada. O mesmo resultado foi encontrado por Debastiani et al. (2016).

A adição da vazão do tempo anterior como variável de entrada proporcionou uma melhora no desempenho dos algoritmos. Este comportamento pode estar associado à sazonalidade das vazões, no caso a $\mathrm{Q}_{\mathrm{t}-1}$, que é dependente da sazonalidade das precipitações na região. Também pode estar relacionada a alta correlação que a vazão atual tem com a do tempo anterior (t-1). A inclusão da vazão antecedente tende a melhorar os resultados por causa da memória do processo hidrológico que dela resulta, sendo a inclusão de variáveis antecedentes já foi utilizada com sucesso em outros estudos, tais como demonstrado por Oliveira et al. (2013), Oliveira et al. (2014), Debastiani et al. (2016).

No período de teste 1 e 2, a MLP apresentou desempenho superior ao da M5P, estando de acordo com os resultados encontrados por Solomatine; Dulal (2003), que alcançaram melhores resultados com o uso da RNA, tendo RMSE de $19,402 \mathrm{~m}^{3} / \mathrm{s}$ e para a M5P encontraram o RMSE de 21,547 $\mathrm{m}^{3} / \mathrm{s}$. Da mesma forma, Bhattacharya; Solomatine (2006) concluíram que o desempenho de uma RNA apresentou resultados ligeiramente superiores aos da M5P quando utilizadas para a modelagem de sedimentos.

Para o período de teste 2, o desempenho entre a MLP e a M5P apresentaram-se bons, e estes foram semelhantes, sendo o RMSE da M5P superior ao da MLP em todos os tratamentos. Tais conclusões também foram ressaltadas por outros estudos como os de Solomatine; Dulal (2003), Bhattacharya; Solomatine (2005), Etemad-Shahidi; Mahjoobi (2009), Gharaei-Manesh et al. (2016), que investigaram o uso de RNA e da M5P para a modelagem de diferentes problemas.

Metodologias semelhantes, porem aplicadas com diversos outros modelos são estudados atualmente, Brighenti et al. (2016) avaliaram o desempenho do modelo SWAT na bacia hidrográfica do Rio Negrinho em Santa Catarina, para a modelagem chuva-vazão. Utilizaram como entrada séries históricas de dados meteorológicos (umidade relativa, radiação, temperatura e velocidade do vento), e dados pluviométricos. Os autores encontraram resultados aceitáveis para o intervalo mensal, com NS variando conforme a alteração da série histórica, sendo entre 0,55 e 0,70 para calibração.

Lucas et al. (2009) aplicaram o modelo hidrológico determinístico mensal de dois parâmetros para simular as vazões mensais das estações localizadas na região do Xingu. Utilizaram como variáveis de entrada séries históricas de 
precipitação e evapotranspiração potencial. Encontraram NS variando de 0,44 a 0,86 .

Hollanda et al. (2015) avaliaram o modelo hidrológico TOPMODEL na estimativa do escoamento superficial na Microbacia Hidrográfica do Córrego Jaqueira, Espírito Santo. O desempenho do modelo para simular eventos isolados de chuva teve NS variando entre 0,03 a 0,81 .

Com o objetivo de comparar uma RNA com a metodologia Box e Jenkins, Batista (2009) utilizou a vazão média mensal como entrada. Concluiu que a RNA produz previsão mais precisa da vazão média mensal, porém a metodologia Box e Jenkins seria mais adequada para extrair informações sobre a série de dados, como por exemplo, identificação de ciclos e tendências.

Zia et al. (2015) utilizaram uma árvore modelo para prever a vazão na bacia hidrográfica Dripsey, no sul da Irlanda. Os autores obtiveram $\mathrm{R}^{2}$ de 0,09 e RMSE de $3,05 \mathrm{~m}^{3} / \mathrm{s}$ ao utilizar a precipitação diária como entrada. Ao utilizarem a precipitação dos últimos cinco dias alcançaram $\mathrm{R}^{2}$ de $0,58 \mathrm{e}$ RMSE de $2,17 \mathrm{~m}^{3} / \mathrm{s}$.

\section{CONCLUSÕES}

$\mathrm{O}$ método árvore modelo $\mathrm{M} 5 \mathrm{P}$ apresentou resultados satisfatórios na simulação da vazão média diária do mês para a bacia do Alto Canoas, quando comparado a MLP. No entanto, a necessidade da poda se mostrou inconclusiva, visto que a mesma foi responsável pela melhora do desempenho em somente metade dos tratamentos.

O melhor conjunto de vetores de entrada foi o uso da precipitação das quatro estações pluviométricas e a vazão média diária do mês anterior $\left(\mathrm{P} 1, \mathrm{P} 2, \mathrm{P} 3, \mathrm{P} 4, \mathrm{Q}_{\mathrm{t}-1}\right)$.

A MLP apresentou desempenho ligeiramente superior ao utilizar a precipitação pontual ao invés de ponderar pela área de contribuição. A variável $\mathrm{Q}_{\mathrm{t}-1}$ foi importante na modelagem e proporcionou ganho de exatidão nas estimativas de vazão.

Uma configuração de MLP apresentada no trabalho mostrou-se superior ao modelo M5P, pois obteve vazões simuladas mais próximas da vazão observada. Apesar disso, recomenda-se a realização de mais testes com a árvore modelo M5P devido a facilidade de sua aplicação.

\section{REFERÊNCIAS}

ANTUNES, T. A. Modelagem hidrológica da bacia hidrográfica do Alto Canoas através do modelo SWAT. 2015. 130f. Dissertação (Mestrado em Engenharia Florestal) - Universidade do Estado de Santa Catarina, Lages, 2015.

BATISTA, A. L. F. Modelos de séries temporais e redes neurais artificiais na previsão de vazão. 2009. $79 \mathrm{f}$. Dissertação (Mestrado em Engenharia de Sistemas) Universidade Federal de Lavras, Lavras, 2009.

BHATTACHARYA, A. B; SOLOMATINE, D. P. Machine learning in sedimentation modelling. Neural networks, New York, v. 19, n. 2, p. 208-214, 2006. DOI: https://dx.doi.org/10.1016/j.neunet.2006.01.007

BHATTACHARYA, B.; SOlOMATINE, D. P. Neural networks and M5 model trees in modelling water lever discharge relationship. Neurocomputing, v. 63, p. 381396, 2005.

DOI: https://dx.doi.org/10.1016/j.neucom.2004.04.016

BRIGHENTI, T. M.; BONUMÁ, N. B.; CHAFFE, P. L. B. Calibração hierárquica do modelo SWAT em uma bacia hidrográfica Catarinense. Revista Brasileira de Recursos
Hídricos, Porto Alegre, v. 21, n. 1, p. 53-64, 2016. DOI: http://dx.doi.org/10.21168/rbrh.v21n1.p53-64

CASTRO, T. N. Modelo de previsão sazonal de chuva para o estado do Ceará baseado em redes neurais artificiais. 2011. 60f. Dissertação (Mestrado em Engenharia Elétrica) - Universidade Federal do Ceará, Fortaleza, 2011.

DANCEY, C.; REIDY, J. Estatística Sem Matemática para Psicologia: Usando SPSS para Windows. Porto Alegre, Artmed, 2006. 608 p.

DEBASTIANI, A. B.; SILVA, R. D.; NETO, S. L. R. Eficácia da arquitetura em modo closed-loop para simulação de um sistema hidrológico. Revista Brasileira de Recursos Hídricos, Porto Alegre, v. 21, n. 4, p. 821-831, 2016. DOI: http://dx.doi.org/10.1590/2318-0331.011615124

ESCARIÃO, R. D.; MONTENEGRO, S. M. G. L.; AZEVEDO, J. R. G.; NETO, A. R. Influência do modelo hidrológico na avaliação da sensibilidade dos recursos hídricos a cenários de mudanças climáticas em região semiárida. Revista Brasileira de Recursos Hídricos, Porto Alegre, v. 17, n. 3, p. 81-91, 2012. DOI: http://dx.doi.org/10.21168/rbrh.v17n3.p81-91

ETEMAD-SHAHIDI, A.; MAHJOOBI, J. Comparison betwenn M5' model tree and neural networks for prediction of significant wave height in lake superior. Ocean engineering, Elmsford, v. 36, n. 15-16, p. 11751181, 2009.2 DOI: https://dx.doi.org/10.1016/j.oceaneng.2009.08.008

FU, L. Neural networks in computer intelligence. New York: McGraw-Hill, 1994. 460 p.

GHARAEI-MANESH, S.; FATHZADEH, A.; TAGHIZADEH-MEHRJARDI, R. Comparison of artificial neural network and decision tree models in estimating spatial distribution of snow depth in a semi-arid region of Iran. Cold Regions Science and Technology, Amsterdam, v. 122, p. 26-35, 2016. DOI: https://dx.doi.org/10.1016/j.coldregions.2015.11.004

GOMES, O. M.; SOUZA, F. A. Z.; SANTOS, C. A. C.; PAIVA, W. Análise geoestatística da precipitação pluvial do estado da Paraíba. Revista Brasileira de Geografia Física, Recife, v. 4, p. 692-702, 2011.

HAGAN, M.T.; MENHAJ, M. Training feed-forward networks with the Marquardt algorithm. IEEE Transactionson Neural Networks, v. 5, n. 6, p. 989-993, 1994.

HAYKIN, S. Redes neurais: princípios e prática. Porto Alegre: Bookman, 2001. 900 p.

HEATH, G. E. Training, testing and validating data set in Neural Network. Disponível em: <http://www.mathworks.com/matlabcentral/newsreader/v iew thread/295781\#917734>. Acesso em: 04 de dez. 2010 .

HOLLANDA, M. P.; CECÍLIO, R. A.; CAMPANHARO, W. A.; ZANETTI, S. S.; ANDRADE, L. N.; GARCIA, G. O. Avaliação do TOPMODEL na estimativa do escoamento superficial em microbacia hidrográfica em diferentes usos. Revista Brasileira de Engenharia Agrícola e Ambiental, Campina Grande, v. 19, n. 5, p. 489-496, 2015. DOI: http://dx.doi.org/10.1590/18071929/agriambi.v19n5p489-496

LUCAS, E. W. M.; SOUSA, F. A. S.; SILVA, F. D. S.; LUCIO, O. S. Modelagem hidrológica determinística e estocástica aplicada à região hidrográfica do Xingu - Pará. Revista Brasileira de Meteorologia, São Paulo, v. 24, n. 
3, p. $\quad 308-322, \quad 2009$. DOI: http://dx.doi.org/10.1590/S0102-77862009000300005

NASH, J. E.; SUTCLIFFE, J. V. River flow forecasting through conceptual models part 1- A discussion of principles. Journal of Hydrology, Amsterdam, v. 10, n. 3, p. 282-290, 1970. DOI: https://dx.doi.org/10.1016/00221694(70)90255-6

OLIVEIRA, G. G.; PEDROLlO, O. C.; CASTRO, N. M. R.; BRAVO J. M. Simulações hidrológicas com diferentes proporções de área controlada na bacia hidrográfica. Revista Brasileira de Recursos Hídricos, Porto Alegre, v. 18, n. 3, p. 193-204, 2013. DOI: http://dx.doi.org/10.21168/rbrh.v18n3.p193-204

OLIVEIRA, G. G.; PEDROLLO, O. C.; CASTRO, N. M. O desempenho das redes neurais artificiais (RNAs) para simulação hidrológica mensal. Revista Brasileira de Recursos Hídricos, Porto Alegre, v. 19, n. 2, p. 251-265, 2014. DOI: http://dx.doi.org/10.21168/rbrh.v19n2.p251265

QUINLAN, J. R. C4.5: Programs for machine learning. São Francisco: Morgan Kaufmann. 1993. 302 p.

QUINLAN, J. R. Learning with continuous classes. In: ADAMS, N.; STERLING, L. (Eds.). Proceedings of the Fifth Australian Joint Conference on Artificial Intelligence. Hobart, Tasmania. Singapore: Worls Scientific, 1992.

SOLOMATINE, D. P.; DULAL, K. N. Model trees as an alternative to neural networks in rainfall-runoff modeling. Hidrological Sciences Jornal, v. 48, n. 3, p. 399-411, 2003. DOI: http://dx.doi.org/10.1623/hysj.48.3.399.45291

SOUSA, W. S.; SOUSA, F. A. S. Rede neural artificial aplicada à previsão de vazão da bacia hidrográfica do rio Piancó. Revista Brasileira de Engenharia Agrícola e Ambiental, Campina Grande, v. 14, n. 2, p.1 73-180, 2010 . DOI: http://dx.doi.org/10.1590/S141543662010000200008

TUCCI, C. E. M. Modelos hidrológicos. 2.ed. Porto Alegre: Editora da UFRGS, 2005. $680 \mathrm{p}$.

WITTEN, I. H.; FRANK, E.; HALL, M. A. Data mining practical machine learning tool and techniques. 3. ed. Elsevier, 2011. 664 p.

ZIA, H.; HARRIS, N.; MERRETT, G.; RIVERS, M. Predicting discharge using a low complexity machine learning model. Computers and Electronics in Agriculture, New York, v. 118, p. 350-360, 2015. DOI: https://dx.doi.org/10.1016/j.compag.2015.09.012 